$\Phi=5$

\title{
Staff members' satisfaction level with the ministry of health and social services strategic plan implementation at three intermediate public hospitals in Namibia
}

\author{
Abner Kukeyinge Shopati ${ }^{1 *}$, Kabwebwe Honore Mitonga ${ }^{2}$, Albert Johannes Isaacs ${ }^{3}$ \\ ${ }^{1}$ University of Namibia, Business School \\ ${ }^{2}$ University of Namibia, School of Public health \\ 3 University of Namibia, Business School \\ *Corresponding author E-mail: shopati.abner@gmail.com
}

\begin{abstract}
This research aims to explore the staff remembers satisfaction level with strategic decisions implementation in the three intermediate public hospitals in Namibia. Reviewing the literature, 27 variables were identified. The items were then reduced using exploratory factor analysis, which is evaluated using Principal Axis Factoring with Direct Oblimin rotation. Using exploratory factor analysis, variables were categorized into 5 implementation perspectives. This model, in the order of effect, identified Service Provision with a predictor importance of (0.79), Human Resources Management (0.07), Governance (0.06), Financial Management (0.05) while, the Infrastructure Development and Management with predictor importance of $(0.03)$ is the least important. This implies that the Service Provision theme is perceived by the MoHSS staff as having the largest impact of implementation satisfaction and quality of service perceptions at the three intermediate public hospitals. The radar chart also shows that the respondents perceived levels of satisfaction with strategy implementation is rated less than desired levels (yellow) of implementation superiority. The only item perceived to perform better than minimum level (blue) is related infrastructures development and management (IDM-2), Improve health facilities to be responsive to emerging needs"'. This implies that the strategic plans implementation level failed to meet the minimum satisfaction level of the operational staff and hospitals management teams. This further implied that top management shall be recognized that operational staff and hospitals management teams can turn strategic plan implementation into success.
\end{abstract}

Keywords: Strategy; Strategic Decision Implementation; Implementation; Adequacy, Superiority; Public Hospital; Factor Analysis.

\section{Introduction}

The MoHSS 2009 -2013 Strategic Plan was preceded by the 2008 health and social services system review and subsequent consultative meetings with the Ministry Staff members across all levels and key stakeholders, who tirelessly identified and outlined critical strategic issues and challenges (MoHSS, 2009). The situational analysis of the plan was done as part of the 2008 Health and Social Services System Review (HSSR). The Strategic Plan encompasses five broad strategic themes: Service Provision: The Ministry sought to focus on core functions, streamline the fragmented services/ programmes/ functions, improve Waste Management, improve fleet management, and improve performance management procedures and systems and other service delivery instruments.

Human-resource management: Recruitment, remuneration and retention policies and strategies were reviewed and upgraded; decision making was devolved to appropriate levels, and staff shortages were vigorously addressed;

Infrastructure development and management: The minimum District Service Packages were defined, sufficient extensions of health services to community level were implemented. Adequate development and maintenance strategies for health facilities were affected, and the often unnecessary and expensive referral system was optimized;
Governance: Addressing problems of inadequate/inappropriate information and communication technologies co-ordination, delayed payment of suppliers, poor record keeping, poor communication and co-ordination, bureaucracy, outdated legislation, policies, guidelines and a lack of a well-defined Strategic Plan;

Financial management: To redress the problem of inequitable distribution of resources, inadequate resource allocation criteria, the need to mobilize more financial resources, and the need to improve financial governance (MoHSS, 2009).

Given the above strategic themes and objectives to be achieved, it was the intention of this study to examine the achievement recorded during the period under review by MOHSS in their annual reports using the MOHSS`s BSC as designed in the strategic plan 2009-2013. Despite, MoHSS setting itself to fulfil its core function, service provision, its main stakeholders, the client still complained about poor service delivery. Sentinel indicators such as malnutrition remained a challenge for MoHSS with stunting levels not declining despite the country's rising income per-capita and government efforts to address food insecurity (MoHSS, 2014b). Stunting levels have stood at 26 percent at the end of 2013 while it expected to be at a strategic target of 15 percent. Additional strategic sentinel targets not met include;

- Underweight levels slightly dropped from 17 percent to 13 percent in the same period, as opposed to the targeted level of 1 percent by 2013 . 
- Wasting has also slightly dropped to 6 percent in 2013 from 8 percent in 2006 .

Another challenge was in the vagueness of strategic plan performance measurement. The measures and/or performance indicators, were not clear whether the data measured was qualitative, quantitative or both and how the percentages were arrived at is another concern of effective measurement of the strategic plan achievements. Accordingly, there is a need to understand the factors contributing to the strategic decisions' implementation failure in $\mathrm{Na}$ mibian public health care, focusing on the how three intermediate public hospitals in Katutura(KISH), Oshakati(OISH) and Rundu (RISH)fared in implementing the 2009-2013 Strategic Plan. Thus the important questions about the study were: What are the staff members' level of satisfaction with implementation of the individual strategic dimensions or strategic themes?. Which strategic theme/dimension is perceived by the MoHSS staff as having the largest impact of implementation satisfaction and quality of service perceptions at the three intermediate public hospitals?

\section{Literature review}

\subsection{Strategic implementation success/failure impact}

To effectively implement the strategies, a unique approach that best suits the internal and external challenges are crucial. Adopting the best approach, however, necessitates addressing the issues of the variables affecting the strategy implementation. This study selects the five themes Service Provision, Human-Resource Management, Infrastructure development and management, Governance and Financial Management as the key variables.

Lega et al. (2013) found that officially adopted strategic plans like the MoHSS 2009 Heath Sector Strategy offer vague and qualitative targets for steering complex PHOs like the three intermediate hospitals. Therefore, the 2009-2013 strategic plan's five themes, have no clear or explicit overarching quantitative strategy and are externally oriented towards the external stakeholders like the government, the public, civic society, NGOs and international organisations. Interestingly, both quarterly and annually reports for the period under reviews were not formulated in line with the strategic themes and its objectives to be achieved, thus MoHSS`s achievement through its strategic plans cannot be quantifiable and failed to meet the minimum standards. Therefore, the proposed framework intends to provide an evaluation framework that can measure the impact of strategic decisions' implementation success or failure on internal stakeholders' satisfaction and quality of service perceptions at the three intermediate public hospitals.

\subsection{Strategy evaluation tool: the balanced score card}

Given that the proposed framework is based on the strategic themes, the framework relies heavily on the MOHSS`s Balanced Score Card that was designed to evaluate the implementation of the strategic plan (MoHSS, 2009). The Balanced Scorecard is an important strategy-evaluation tool that allows organisations to evaluate strategies from four perspectives namely, financial performance, customer knowledge, internal business processes and learning and growth (David, 2011). The Balanced Scorecard (BSC) developed by Robert S. Kaplan and David P. Norton (1992) is probably the most renowned performance measurement framework for strategic plan implementation. The reason for this is that Kaplan and Norton most notably broadened the understanding of performance by multiple dimensions. Based on a one-year research project and numerous interviews, Kaplan and Norton developed the balanced scorecard as a tool for top management, which provides a multi-dimensional overview of company performance (Kaplan and Norton, 1992).

According to David (2011) the Balanced Scorecard analysis assist organisations in answering the how questions on effectively strategy implemented. These include questions such as:
- How well is the organization continually improving and creating value along measures such as innovation, technological leadership, service quality, operational process efficiencies, and so on?

- How well is the organization sustaining and even improving upon its core competencies and competitive advantages?

- How satisfied are the organization's customers?

As such, the Balanced Scorecard approach balances the long-term with short-term concerns, as well as balance financial with nonfinancial concerns and internal with external concerns (David, 2011). It can be an excellent management tool, as used by MoHSS in its 2009-2013 Health Sector Strategic Plan. The tool has proven effective to organisations from in various industries with the same underlying theme of being able to evaluate the organization's strategies based upon both keys quantitative and qualitative measures. However, failure to meet the basic requirements such as economical strategy evaluation activities, having just the right information and not having too many controls. Strategy-evaluation activities should be meaningfully providing managers with useful information about tasks that can control and influence in a timely manner (David, 2011).

Large organizations like the three intermediate hospitals require a more elaborate and detailed strategy-evaluation system because it is more difficult to coordinate efforts among different divisions and functional areas within the hospital hence strategic implementation Committee could be the best option for effective implementation and coordination. Unlike, managers in smaller establishments who often communicate daily with each other and their employees and do not need extensive evaluative reporting systems. Thus MoHSS failed to meet the basic requirements needed for its strategic plan to be effective, by not establishing specific hospital-based strategic plans implementation committees and using a top-down approach of developing national and ministeriallevel strategic plans. It further observed that at MoHSS, the strategic evaluation activities are often done centrally by the department of policy and planning that is often not familiar with hospital environments and thus leave the gathering and evaluating information for these large institutions to the top management of these institutions. The challenge to this strategy-evaluation system is in the ability to convince these top managers that failure to accomplish certain objectives within a prescribed time is not necessarily a reflection of their performance, because their performance agreements are aligned to this strategy evaluation system.

David (2011) argues that there is no one ideal strategy-evaluation system and that the unique characteristics of the organization, including its size, management style, purpose, problems, and strengths should determine the strategy-evaluation and control system's final design. He notes that successful organizations' strategy-evaluation and control system are such that they treat facts as friends and controls as liberating. Successful organisations not only survive but thrive in the troubled waters due to their strategy evaluation and control systems, which are sound.

\section{Research methodology}

Questionnaires were used, and respondents were asked to rate quality service indicators of MoHSS Balance Score Card (BSC) based on LibQual rating's three columns from 0 (low) to 9 (high) scales for "perception," "desire," and "minimum" services. The minimum and desired service expectations were considered indicators of the importance of the service (attribute or dimension item) to the respondents' users. We have determined the most important areas for service improvement by identifying the items that ranked highest by respondent on minimum/desired service level. The minimum expectations of level of service that users consider as adequate represent their minimum level of service that users will tolerate or willing to accept. The services performed below respondent' minimum expectations could create disappointment, frustration and dissatisfaction as well as decrease their loyalty and reliability of effective strategic plan implementation. 
Thus a radar chart is used to present these expectations and satisfaction levels with the Radar Chart axis representing the 27 core survey questions of the Ministry of Health and Social Services Balance score card of the strategic plan. Figure 5.1 presents the results.

\section{Data analysis}

\subsection{The results of exploratory factor analysis}

The strength to the relationship among the variables (or items) is tested using the Kaiser-Meyer-Olkin (KMO) test, which must produce a value larger than 0.5 . And, the items within the scales should adequately correlate with a Bartlett's test of sphericity that should be significant $(\mathrm{p}<.05)$ (Pallant, 2010). The study results showed that all the necessary conditions were met and that it is appropriate to conduct an Exploratory Factor Analysis.

\subsection{Libqual item scale analysis}

In order to determine the strategic plan implementation success and/or failure as expressed by workers and management, this study adopted LibQual model of service quality measurement to measure respondents' minimum, desired and perceived levels of strategic plan implementation of the dimensions highlighted above.

In achieving the objectives of the study, the LibQual radar chart is used to present the descriptive statistics at the level of satisfaction with the MoHSS strategic plan objectives for 2009 - 2013 implementation. Multivariate regression analyses procedures are used to explore the nature of the relationships between level of satisfaction with implementation of the individual strategic dimensions or strategic themes, and the critical success factors required for successful implementation. The questionnaire was reviewed in terms of validity and reliability; Cronbach's alpha was 78\%-90\%. It shows high reliability of the questionnaire. The final questionnaire was distributed among MoHSS Staff. Data analysis was performed by SPSS 23 software. Research period was limited to April 2016 - May 2016

Figure1 presents the results of expectations and satisfaction levels with the Radar Chart axis representing the 27 core survey questions of the Ministry of Health and Social Services` Balance score card of the strategic plan.
Perceived Greater Than Desired

Perceived Greater Than Minimum

\section{$\square$ Percceived Less Than Desired \\ $\square$ Percieved Less Than the Minum}

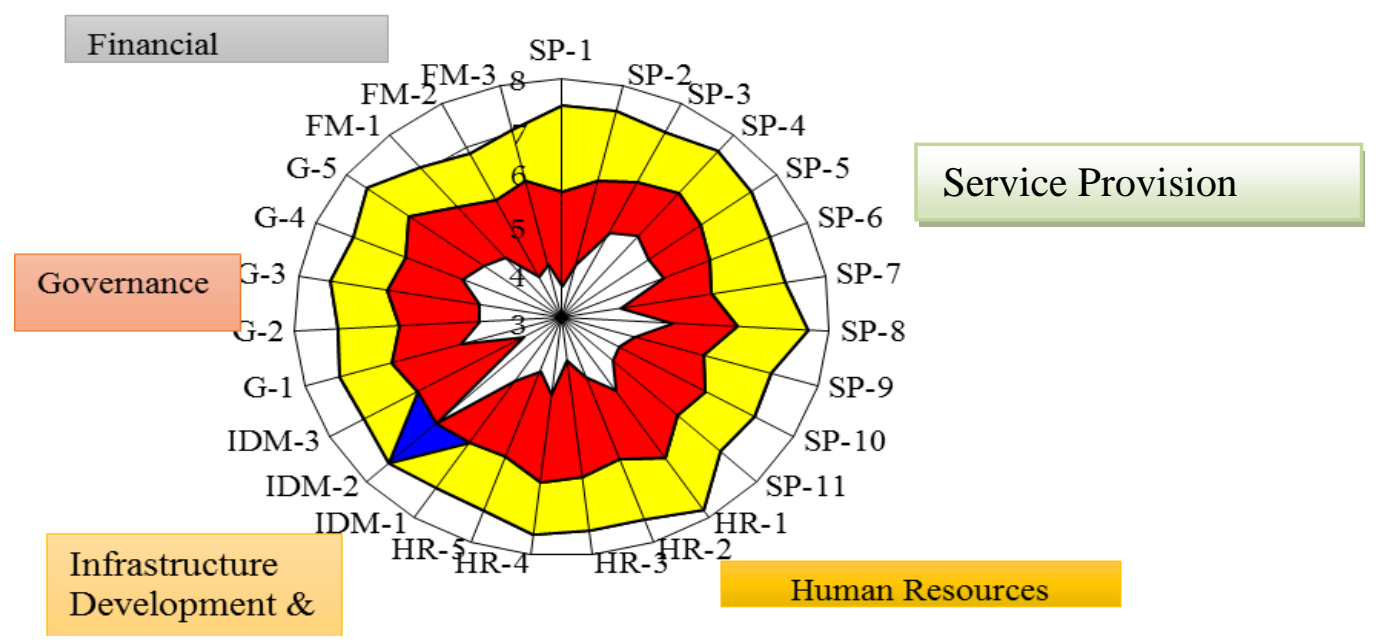

Fig. 1: Radar Chart of Satisfaction with Implementation of MOHSS Strategic Plan Objectives.

Figure 1 presents the statistical data of the respondents' satisfaction in terms of how the strategic plan objective meet the minimum required implementation level of the respondents. The Radar Chart in figure 5.1 shows the aggregate results for the 27 Section A. survey questions responses. On each axis, respondents' minimum level, desired level and perceived levels of satisfaction with the strategic plan are plotted and the resulting "gaps" between the three levels represents implementation adequacy or implementation superiority depending on the shade of colour. The five dimensions or Strategy Themes are grouped together and labelled: Service Provision, Human Resource Management, Infrastructure development and management, Governance and Financial Management. Figure 1 shows that overall the respondents are not adequately satisfied with strategic plan implementation as seen from the high concentrations of the red and yellow shades. The implementation of the strategic plan objectives is not meeting the minimum levels of satisfaction required by the respondents with only one item in blue, others are perceived to perform less than the minimum (red) implementation adequacy. The chart also shows that the respondents perceived levels of satisfaction with strategy implementation is rated less than desired levels (yellow) of implementation superiority. The only item perceived perform better than minimum level (blue) is related infrastructures development and management (IDM-2), "Improve health facilities to be responsive to emerging needs"'.

\subsection{Expected Implementation Satisfaction (EIS)}

The Expected Implementation Satisfaction (EIS) scale includes 27 items consist of the following five factors, namely; service provision (11 items), governance (5 items), infrastructure development (3 items); human resource management (5 items) and financial management (3 items)

\subsection{Service provision}

From the 11-item service provision theme (SERVPRO) scale, only one significant factor is extracted (see Table 1). This factor produced an eigenvalue of 10.451 and explained 95.011 percent of the variance in SERVPRO (factor loadings: $0.957<\mathrm{r}<0.979$ ). The scale is thus unidimensional such that a single factor model will constitute a good fit to the data for each of the examined service provision objectives. 
Table 1: Results of the Factor Analysis on SERVPRO Scale

\begin{tabular}{|c|c|c|}
\hline $\begin{array}{l}\text { Cod } \\
\text { e }\end{array}$ & Description & $\begin{array}{l}\text { SERVPR } \\
\text { O }\end{array}$ \\
\hline $\begin{array}{l}\text { SP- } \\
2\end{array}$ & Improve Focus on core function. & 0.979 \\
\hline SP- & Provision Improve fleet management. & 0.979 \\
\hline 3 & Improve waste management system. & 0.978 \\
\hline SP1 & Ensure prompt and effective response to disasters. & 0.974 \\
\hline $\begin{array}{l}\text { SP- } \\
9\end{array}$ & Decrease morbidity rates. & 0.973 \\
\hline $\begin{array}{l}\text { SP- } \\
6\end{array}$ & Improve stakeholder relationships and co-ordination. & 0.973 \\
\hline $\begin{array}{l}\text { SP- } \\
5\end{array}$ & $\begin{array}{l}\text { Provide adequate, formalised and structured community } \\
\text { based } \\
\text { health services. }\end{array}$ & 0.972 \\
\hline Sp1 & Decrease mortality rates. & 0.972 \\
\hline $\begin{array}{l}\text { SP- } \\
8\end{array}$ & Reduce malnutrition. & 0.970 \\
\hline SP- & Streamline and harmonise services/functions/programs. & 0.968 \\
\hline SP- & $\begin{array}{l}\text { Adopt and implement performance management system } \\
\text { at all level. }\end{array}$ & 0.957 \\
\hline \multicolumn{2}{|c|}{ Eigenvalue } & $\begin{array}{l}10.45 \\
1\end{array}$ \\
\hline \multicolumn{2}{|c|}{$\%$ of Variance } & $\begin{array}{l}95.01 \\
1\end{array}$ \\
\hline \multicolumn{2}{|c|}{ Cumulative $\%$} & $\begin{array}{l}95.01 \\
1\end{array}$ \\
\hline
\end{tabular}

Notes. SERVPRO = Service Provision

\subsection{Governance}

From the 5-item governance theme (GOVERN) scale, only one significant factor is extracted from 5-items (see Table 2). This factor produced an eigenvalue of 3.349 and explained 66.98 percent of the variance in GOVERN (factor loadings: $0.601<\mathrm{r}<$ 0.919). Further analysis with ANOVA shows that there is no significant difference between the item means $(\mathrm{F}=4.429, \mathrm{p}=0.002)$. GOVERN scale is also a unidimensional factor. See Table 5.8 for the full set of item-level factor loadings, eigenvalues and variance explained.

Table 2: Results of the Factor Analysis on GOVERN Scale

\begin{tabular}{lll}
\hline Code & Item Description & GOVERN \\
\hline G-4 & Improve procurement and payment system. & 0.773 \\
G-5 & Strengthen the stewardship role of the MOHSS. & 0.891 \\
G-1 & Ensure responsive legislation and policies. & 0.635 \\
G-2 & Implement efficient and effective contract manage- & 0.601 \\
G-3 & Impnt system. & 0.919 \\
Eigenvalue & 3.349 \\
$\%$ of Variance & 66.983 \\
Cumulative \% & 66.983 \\
\hline
\end{tabular}

Note: GOVERN= Governance

\subsection{Human resource management}

From the 5-item human resource management theme (HRM) scale, only one significant factor is extracted from 5 -items (see Table 3). This factor produced an eigenvalue of 3.349 and explained 66.98 percent of the variance in HRM (factor loadings: $0.642<\mathrm{r}<0.798$ ). Further analysis with ANOVA shows that there is no significant difference between the item means $(\mathrm{F}=15.296, \mathrm{p}=0.000)$. HRM scale is unidimensional. Table 5.9 presents the item-level factor loadings, eigenvalues and variance explained.
Table 3: Results of the Factor Analysis on HRM Scale

\begin{tabular}{|c|c|c|}
\hline Code & Item Description & HRM \\
\hline HR-3 & Improve staff morale. & 0.798 \\
\hline HR-2 & $\begin{array}{l}\text { Ensure adequate and appropriate staff complement and } \\
\text { strength. }\end{array}$ & 0.790 \\
\hline HR-4 & Create skilled work force. & 0.785 \\
\hline HR-5 & $\begin{array}{l}\text { Devolve levels of decision making to appropriate lev- } \\
\text { els. }\end{array}$ & 0.764 \\
\hline HR-1 & $\begin{array}{l}\text { Improve conditions of services for health and social } \\
\text { workers. }\end{array}$ & 0.642 \\
\hline \multicolumn{2}{|c|}{ Eigenvalue } & 3.288 \\
\hline \multicolumn{2}{|c|}{$\%$ of Variance } & 65.763 \\
\hline \multicolumn{2}{|c|}{ Cumulative \% } & 65.763 \\
\hline
\end{tabular}

\subsection{Infrastructure development and management (IDM)}

The 3-item Infrastructure development and management (IDM) factor produced an eigenvalue of 2.095 and explained 69.846 percent of the variance in IDM (factor loadings: $0.708<\mathrm{r}<0.763$ ). (See Table 4).

\begin{tabular}{lll}
\multicolumn{3}{c}{ Table 4: Results of the Factor Analysis on IDM Scale } \\
\hline Code & Item Description & IDM \\
\cline { 1 - 1 } IDM-2 & $\begin{array}{l}\text { Improve health facilities to be responsive to emerging } \\
\text { needs }\end{array}$ & 0.763 \\
IDM-1 & $\begin{array}{l}\text { Ensure proper management of infrastructure and } \\
\text { equipment }\end{array}$ & 0.750 \\
IDM-3 & Provide a minimum district service package (MDSP) & 0.708 \\
Eigenvalue & 2.095 \\
\% of Variance & 69.846 \\
Cumulative \% & 69.846 \\
\hline
\end{tabular}

\subsection{Finance management (FM)}

The 3-item finance management (FM) factor produced an eigenvalue of 3.349 and explained 66.98 percent of the variance in FM (factor loadings: $0.642<\mathrm{r}<0.798$ ). Further analysis with ANOVA shows that there is no significant difference between the item means $(\mathrm{F}=17.99, \mathrm{p}=0.000)$. Table 5 presents the results.

Table 5: Results of the Factor Analysis on FM Scale

\begin{tabular}{lll}
\hline Code & Item Description & FM \\
\hline FM-2 & $\begin{array}{l}\text { Ensure capital formation make up at least 10\% } \\
\text { MOHSS total budget }\end{array}$ & 0.899 \\
FM-1 & $\begin{array}{l}\text { Improve financial management } \\
\text { FM-3 } \quad \begin{array}{l}\text { Ensure equitable and efficient allocation of resources } \\
\text { among the ministry`s directorates }\end{array}\end{array}$ & 0.864 \\
Eigenvalue & 0.812 \\
\% of Variance & 3.288 \\
Cumulative \% & 65.763 \\
\hline
\end{tabular}

\subsection{Expected Implementation Satisfaction (EIS)}

A forward stepwise multiple linear regression model is used to explore the relationship between EIS and the five EIS themes.Figure 2 presents the model summary. 
Model Summary

\begin{tabular}{|l|l|}
\hline Target & $\begin{array}{l}\text { EIS(FM,IDM,HRM,GOVERN, } \\
\text { SERVPRO) }\end{array}$ \\
\hline Automatic Data Preparation & On \\
\hline Model Selection Method & Forward Stepwise \\
\hline Information Criterion & \\
\hline
\end{tabular}

The information criterion is used to compare to models. Models with smaller information criterion values fit better. The information criterion cannot be computed because the model has perfect fit.

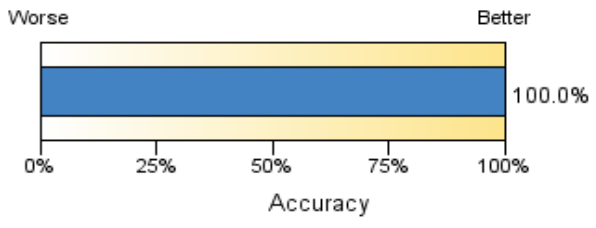

Figure 2 shows that a model accuracy of 100 percent because the model is a perfect fit. This confirms that the five themes are significant to the successful implementation of the strategy and the consequent satisfaction of the MoHSS staff. Additionally, Figure 3 presents the predictor importance of the themes to EIS.

Amongst the five predictor themes of EIS, Service Provision with a predictor importance of 0.79 is the most important predictor of EIS values. While, the Infrastructure Development and Management with predictor importance of 0.03 is the least important. This implies that the Service Provision theme is perceived by the MoHSS staff as having the largest impact of implementation satisfaction and quality of service perceptions at the three intermediate public hospitals. Figure 4 presents the predictor coefficients and the EIS model equation.

Fig. 2: EIS Model Summary.

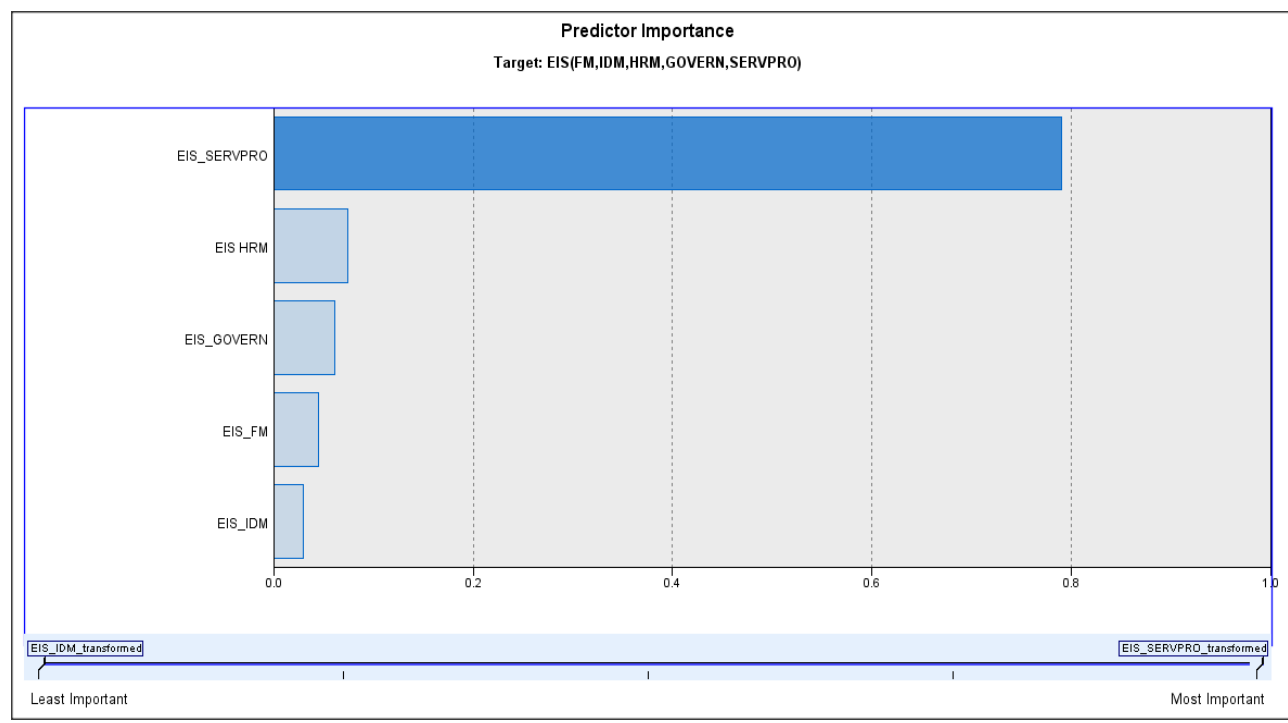

Fig. 3: Predictor Importance for EIS.

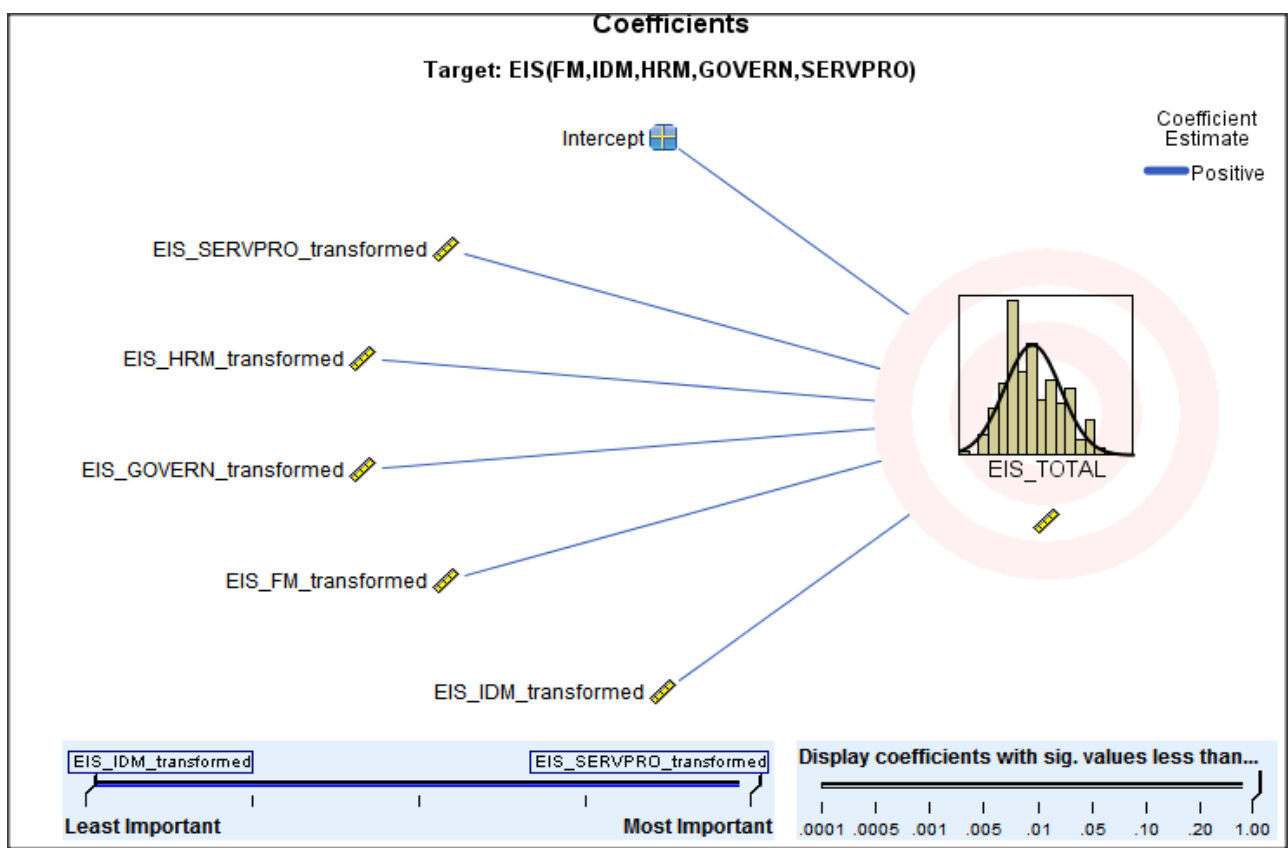

Fig. 4: Model 1 Coefficients (EIS). 
From the Coefficients Figure 4, the equation used to predict EIS can be derived from the standardized Coefficients (B) as:

\section{EIS Total $=$ EIS_FM + EIS_IDM + EIS HRM + EIS_GOVERN + EIS_SERVPRO}

\section{(Model EIS Total)}

The standardized coefficients of the predictor variables are statistically significantly different to zero at the $p<.001$ level.

This model, in the order of effect, identified Service Provision with a predictor importance of (0.79) is the most important predictor of EIS values, Human Resources Management(0.07), Governance(0.06), Financial Management(0.05) while, the Infrastructure Development and Management with predictor importance of 0.03 is the least important. This implies that the Service Provision theme is perceived by the MoHSS staff as having the largest impact of implementation satisfaction and quality of service perceptions at the three intermediate public hospitals.

The radar chart also shows that the respondents perceived levels of satisfaction with strategy implementation is rated less than desired levels (yellow) of implementation superiority. The only item perceived perform better than minimum level (blue) is related infrastructures development and management (IDM-2), "Improve health facilities to be responsive to emerging needs'.

This implies that the strategic plans implementation level failed to meet the minimum satisfaction level of the operational staff and hospitals management teams.

\section{Conclusion}

Nowadays, public health care is faced with challenges of technology and innovation of new products and services in order to provide patient-centred services. It is therefore crucial for hospitals management to understand that hopsitals are complex organisations characterised by complicated organizational structures and complex interactions, power of interest groups and internal politics, and vulnerability to the external environment. Thus hospital managers shall recognised that strategy implementation is a dynamic, iterative and complex process, which is comprised of a series of decisions and activities by managers, employees and affected by number of interrelated internal and external factors to turn strategic plans into reality in order to achieve strategic objectives. Reviewing the literature, 27 variables were identified. The items were then reduced using exploratory factor analysis which is evaluated using Principal Axis Factoring with Direct Oblimin rotation. Using exploratory factor analysis, variables were categorized into 5 implementation perspectives. This model, in the order of effect, identified Service Provision with a predictor importance of (0.79), Human Resources Management (0.07), Governance (0.06), Financial Management (0.05) while, the Infrastructure Development and Management with predictor importance of (0.03) is the least important. This implies that the Service Provision theme is perceived by the MoHSS staff as having the largest impact of implementation satisfaction and quality of service perceptions at the three intermediate public hospitals. The radar chart also shows that the respondents perceived levels of satisfaction with strategy implementation is rated less than desired levels (yellow) of implementation superiority. The only item perceived perform better than minimum level (blue) is related infrastructures development and management (IDM-2), "Improve health facilities to be responsive to emerging needs". This implies that the strategic plans implementation level failed to meet the minimum satisfaction level of the operational staff and hospitals management teams.

This further implied that top management shall recognized that operational staff can turn strategic plan implementation into success.

In conclusion, David (2011) reminds us that formulating a plan may be difficult, but implement strategies is even more difficult. Therefore, Strategic plans implementation in hospitals has to do with the practices and processes that are adopted (how) and the practitioners (strategists) involved (who).

\section{Funding}

This work was supported by a grant from National Commission on Research, Science and Technology (NCRST) Namibia, 2016.

\section{References}

[1] Alexander, L. D. (1991). Strategy implementation: nature of the problem", . (D. Hussey, Ed.) International Review of Strategic Management, 2(1), 73-96.

[2] Alotaibi, Y., \& Liu, F. (2016). Business process modelling framework derive and implement IT goals:a case study. Int. J. Industrial and Systems Engineering , 22(2), 161-190. https://doi.org/10.1504/IJISE.2016.073961.

[3] Card, D., Dobkin, C., \& Maestas, N. (2009). Does Medicare Save Lives? Quarterly Journal of Economics, 597-636. https://doi.org/10.1162/qjec.2009.124.2.597.

[4] Chawla, M., \& Govindaraj, R. (1996). Improving Hospital Performance through Policies to Increase Hospital Autonomy: Implementation Guidelines. Health Care Financing and Private Sector Development portfolio, AFR/SD/Health and Human Resources for Africa (HHRAA) Project. Washington: USAID/.

[5] Clark, C. E. (1962). A Pert Model for tlie distribution of an activity. Operations Research, 405-406. https://doi.org/10.1287/opre.10.3.405.

[6] Clements, B., Coady, D., \& Gupta, S. (2012). The economics of public health care reform in advanced and emerging economies. In B. Clements, D. Coady, \& S. Gupta, The economics of public health care reform in advanced and emerging economies (pp. 323). Washington D.C: IMF.

[7] David, F. R. (2011). Strategic management: concepts and cases (13th ed.). New Jersey: Prentice Hall.

[8] De Vos, A. S., Strydom, H., Fouche, C. B., \& Delport, C. S. (2011). Research at grass roots: For the social sciences and human service professions. (4th ed.). Pretoria: Van Schaik Publishers.

[9] Hair, J. F., Black, W. C., Babin, B. J., Anderson, R. E., \& Tatham, R. L. (2013). Multivariate Data Analysis (7th ed.). USA: Pearson Prentice Hall.

[10] Hernon, P. (2002). Quality: New directions in the research. The Journal of Academic Librarianship, 28, 224-231. https://doi.org/10.1016/S0099-1333(02)00286-0.

[11] Jakab, M. (2007). An Empirical Evaluation of the Kyrgyz Health Reform: Does It Work for the Poor? Harvard School of Public Health, Department of Health Policy and Management. Cambridge, MA: Harvard University.

[12] Joumard, I., Andre, C., \& Nicq, C. (2010). Health Care Systems: Efficiency and Institutions. Economics Department Working Paper No. 769 . Paris: Organization for Economic Cooperation and Development. https://doi.org/10.1787/5kmfp51f5f9t-en.

[13] Kathora, H., \& Strauss, E. (2012). A follow-up report of the Auditor-General on performance audit study on MoHSS-referral system for the financial years 2008, 2009 and 2010. Windhoek: Office of the Auditor-General.

[14] Kline, P. (1994). An Easy Guide For Factor Analysis . New York, USA: Routledge.

[15] Kobus, M. (2013). First Steps in Research (13th ed.). Pretoria: Van Schaik Publisher.

[16] Latif, B., Gohar, F. R., Hussain, A., \& Kashif, M. M. (2013). Barriers to Effective Strategic Planning. International Journal of Management \& Organizational Studies, 1(2), 16-21.

[17] Lau, A. T. (1999). Making sense of contemporary strategic implementation: towards a conceptual model. Public Administration \& Management: An Interactive Journal, 4(4), 494507.

[18] Leedy, P. D., \& Ormrod, J. E. (2010). Practice Research: Planning and Design. New York: Pearson.

[19] Lega, F., Longo, F., \& Andrea, R. ( 2013 ). Decoupling the use and meaning of strategic plans in public healthcare. BMC Health Services Research, 13(5). Retrieved October 28, 2015, from http://www.biomedcentral.com/1472-6963/13/5. https://doi.org/10.1186/1472-6963-13-5.

[20] Low, A., de Coeyere, D., Shivute, N., \& Brandt, L. (2001). Patient referral patterns in Namibia: identification of potential to improve 
the efficiency of the health care system. International Journal of Health Planning and Management, 16 https://doi.org/10.1002/hpm.628.

[21] Mahadevan, B. (2007). Operations Management: Theory \& Practice. London: Pearson Education.

[22] Marcinko, D. E., \& Hetico, H. R. (2014). Financial ManagementStrategies for Hospitals andHealthcare Organizations: Tools, Techniques, Checklists and Case Studies . Boca Raton, FL: CRC Press.

[23] Meyer, V. (., Pascucci, L., \& Murphy, J. P. (2012, May ). Implementing Strategies in Complex Systems: Lessons from Brazilian Hospitals . BAR, 9(Special Issue, art. 2), 19-37.

[24] MoHSS. (2000). Demographic and Health Survey. Windhoek: Ministry of Health and Social Services.

[25] MoHSS. (2007). Demographic and Health Survey. Windhoek: Ministry of Health and Social Services.

[26] MoHSS. (2008). Health and Social Services System Review. Windhoek: Ministry of Health and Social Services.

[27] MoHSS. (2009). 2009 - 2013 Strategic Plan. Windhoek: Ministry of Health and Social Services.

[28] MoHSS. (2010). National Health Policy Framework 2010-2020 . Windhoek: Ministry of Health and Social Services. Retrieved from http://www.healthnet.org.na

[29] MoHSS. (2013a). National Referral Policy. Windhoek: Ministry of Health and Social Services.

[30] MoHSS. (2014a). Report of the National HIV Sentinel Survey. Windhoek, Namibia: Ministry of Health and Social Services.

[31] MoHSS. (2014b). Namibia Child Survival Strategy 2014-2018. Windhoek: MInistry of Health and Social Services.

[32] MoHSS. (2015, June). Namibia 2012/13 Health Accounts Report. Windhoek, Namibia: Ministry of Health and Social Services.

[33] MoHSS/NSA. (2013). Namibia Demographic and Health Survey Windhoek: Ministry of Health and Social Services/Namibia Statistics Agency.

[34] MoHSS-ICF. (2011, February). Health Facility Census (HFC) 2009. Windhoek: Ministry of Health and Social Services (MoHSS) and ICF Macro.

[35] Murante, A. M. (2010). Patient satisfaction: a strategic tool for health services management. Doctor of Philosophy Thesis. Scuola Superiore Sant'Anna.

[36] Nowicki, M. (2004). The financial management of hospitals and healthcare organizations. Chicago: Health Administration Press.

[37] NSA. (2012). Namibia 2011 Population and Housing Census. Windhoek: Namibia Statistics Agency (NSA).

[38] Office of the President. (2013). Presidential Commission of Inquiry on Health and Social Services. Windhoek: Government Printer.

[39] Pallant, J. (2010). SPSS survival manual: A step by step guide to data analysis using SPSS. England: Open University Press.

[40] Parasuraman, A., Berry, L. L., \& Zeithaml, V. A. (1991). Refinement and reassessment of the SERVQUAL Scale. Journal of Retailing, 67, 420-450.

[41] Parasuraman, A., Zeithaml, V. A., \& Berry, L. L. (1985). A conceptual model of service quality and its implications for future research . Journal of Marketing, 49(4), 41-50. https://doi.org/10.2307/1251430.

[42] Pleguezuelo, R. H., Pérez, J. G., \& Rambaud, S. C. (2003, January). A note on the reasonableness of PERT hypotheses. Operations Research Letters, 31(1), pp. 60-62. Retrieved from http://dx.doi.org/10.1016/S0167-6377(02)

[43] Pomp, M., \& Vujic, S. (2008). Rising Health Spending, New Medical Technology, and the Baumol Effect. Discussion Paper No. 115. The Hague: Netherlands Bureau for Economic Policy Analysis.

[44] Reyes-Alcázar, V., Torres-Olivera, A., Núñez-García, D., \& Almuedo-Paz, A. (2012). Critical Success Factors for Quality Assurance in Healthcare Organizations. In M. Savsar, Quality Assurance and Management (pp. 267-289). Rijeka, Croatia: InTech Europe. Retrieved August 20, 2015, from http://www.intechopen.com/books/quality-assurance-andmanagement/critical-success-factors-for-qualityassurance-inhealthcare-organisations

[45] Saunders, C. (2014). Introduction to Research and Research Methods. Bradford: University of Bradford.

[46] Savedoff, W. (2007). What Should a Country Spend on Health Care? Health Affairs, 26(4), 962-970. https://doi.org/10.1377/hlthaff.26.4.962.

[47] Sial, A., Usman, M. K., Zufiqar, S., Satti, A. M., \& Khursheed, I. (2013). Why Do Public Sector Organisations Fail In Implementation of Strategic Plan in Pakistan. Public Policy and Adminstration Research, 3(1), 222-573.
[48] Thompson, J. M., Buchbinder, S. B., \& Shanks, N. H. (2012). An overview of healthcare management. ,. In S. B. Buchbinder, \& N. H. Shanks, Introduction to Health Care Management (pp. 1-16) Jones and Bartlett Inc.

[49] Vaidya, K., Sajeev, A. S., \& Callender, G. (2006). Critical Factors That Influence E-Procurement Implementation Success In The Public Sector. Journal of Public Procurement, 6(1\&3), 70-99.

[50] Webster, T. R., Mantopoulos, J., Jackson, E., Cole-Lewis, H., Kidane, L., Kebede, S., . . . Bradley, E. H. (2011, April 30). A brief questionnaire for assessing patient healthcare experiences in lowincome settings. International Journal of Quality Health Care 23(3), 258-268. https://doi.org/10.1093/intqhc/mzr019.

[51] Wegner, T. (2010). Applied Business Statistics: Methods and Excelbased Applications. Cape Town, South Africa: Juta \& Co. Ltd.

[52] Welman, C., Kruger, F., \& Mitchell, B. (2010). Research Methodology. South Africa: Oxford.

[53] WHO. (2010). The World Health Report 2010 - Health Systems:Improving Performance. Geneva: World Health Organization (WHO).

[54] World Bank. (2010, May 22). Namibia Health Sector Note (P110113). Health, Nutrition and Population, Southern Africa Country Department I. Washington D.C: World Bank.

[55] Yang, L., Guohui, S., \& Eppler, M. J. (2008 ). Making Strategy Work: A Literature Review on the Factors influencing Strategy Implementation . ICA Working Paper 2. Institute of Corporate Communication.

[56] Zikmund, W. G., \& Babin, B. J. (2010). Essentials Of Marketing Research (4th ed.). Mason, $\mathrm{OH}$ : South-Western, Cengege Learning. 